\title{
The accessibility assessment and the regional range of transit- oriented development: An application of schedule accessibility measures in the Nord Pas-de-Calais region
}

\author{
Alexis Conesa \\ Université de Strasbourg \\ conesa@unistra.fr
}

Abstract: Transit-oriented development (TOD) arouses a great deal of interest as the interaction between transport and land use becomes a key topic in regional and urban planning. Even though accessibility is a key driving factor, it is barely assessed with accuracy. In Europe, the scope of TOD effects is large. It strongly influences the development of regional transport. Regarding that, this research brings forward a method that is based on multiscale accessibility measures to evaluate TOD strategy in a metropolitan European region. Hence, it proposes a multiscale accessibility method. On one hand, it introduces the pedestrian accessibility indicators at the local scale. On the other hand, it tackles the schedule accessibility measures in a constraints-based approach at the regional scale. This method is implemented in assessing the potential of TOD strategy in Nord Pas-de-Calais (France). For that, two TOD scenarios are presented. The first one tackles the main metropolitan center but does not include downtown. The second one deals with a second-order peripheral pole. These scenarios present difficulties in gathering both an effective local TOD and a sustainable development policy at the regional scale. However, a TOD center can enhance the intermediate scale urban centrality when using intermediate schedule accessibility measures (for coaches and buses). Furthermore, the indicators about the rail transit system highlight an uncertainty in the regional effects, which can only be solved by applying a major and expensive policy. The final remarks pave the way for further research regarding a full-fledged regional TOD strategy that includes a wellordered dissemination of TOD centers.

Keywords: Schedule accessibility, transit-oriented development, rail, multiscale accessibility, regional transport strategy

\section{Article history:}

Received: September 28, 2015

Received in revised form:

September 18, 2017

Accepted: November 29, 2017

Available online: January 26,

2018

\section{Introduction}

With the increase in the sustainability concerns, the assessment of transport policies and land-use developments becomes a central issue in the urban planning. Accordingly, accessibility is undoubtedly a

Copyright 2018 Alexis Conesa

http://dx.doi.org/10.5198/jtlu.2018.850

ISSN: 1938-7849 | Licensed under the Creative Commons Attribution - Noncommercial License 3.0

The Journal of Transport and Land Use is the official journal of the World Society for Transport and Land Use (WSTLUR) and is published and sponsored by the University of Minnesota Center for Transportation Studies. 
relevant tool. During the last couple of decades, "Transit-Oriented Development" (Calthorpe, 1993) has put forward an urban development strategy that is based on the city and transit interplay (Cervero, 1989). This approach aims at containing the urban sprawl, congestion reduction, local-scale shopping enhancement and cohesive neighborhood creation. TOD targets the mass-transit station surroundings where the population has access to services and goods without using private cars (Curtis, Renne, $\&$ Bertolini, 2009). TOD principles are usually defined as the 5Ds: Density, Diversity, Design, Destination accessibility and Distance to transit (Cervero \& Kockelman, 1997; Litman, 2010). The critical role of accessibility in the land-use issues is well acknowledged (Handy, 1994; Bristow, Farrington, Shaw, \& Richardson, 2009). However, accessibility is seldom explicitly measured when assessing TOD projects. For instance, the Transportation Research Board (2007) selects the "ten most useful indicators to measure the success of Transit-Oriented development," in which no accessibility indicator appears. ${ }^{1}$ With respect to that, this paper addresses Destination accessibility and Distance to transit topics.

Actually, two levels of mobility must be studied in measuring the accessibility in TOD projects. The first one is the metropolitan scale mobility, which relies on a mass-transit system. The second one is the pedestrian or biking mobility (Wu, Shen, \& Zu, 2011). Several studies regarding TOD deal with walking and biking issues although they do not explicitly provide accessibility measures (Marshall \& Garrick, 2010; Leslie, Butterworth, \& Edwards, 2006). Besides, the rail offers a competitive transport service at the regional scale. It is the pertinent travel mode to be assessed. It is interesting to note that TOD has evolved into a regional or "network" approach in Europe, relying on the regional services rather than Light Rail (Bertolini, Le Clercq, \& Kapoen, 2005; Knowles, 2012; Papa, Moccia, Angiello, \& Inglese, 2013). In fact, the anti-sprawl and transit ridership policies in Europe are, inherently, linked up with the regional planning and the polycentric scheme. This relationship is due to the combination of a dense built environment and a strong influence of the historical city centers (Newman \& Jennings, 2008; Curtis et al., 2009). This broader geographical scale can be witnessed in the famous Dutch Stedenbaan project, which stands as a successful TOD implementation at the regional scale (Balz \& Shrijnen, 2011). During this kind of project assessment, it is frequently referred to the regional-scale accessibility. Yet, the appropriate and realistic methods, which put forward the schedule accessibility measures based on the train timetables, remain quite rare.

A regional TOD strategy involves several projects, which correspond to several train stations and illustrate the Extended-TOD or E-TOD concept (Schneider, 2012). It is pointed out that the "basic TOD concept often leads to the implementation of a one-size-fits-all set of solutions" (Dittmar \& Poticha, 2004) even though urban areas have not an isotropic structure, especially in Europe (Newman $\&$ Kenworthy, 1989). Thus, various stations must foster various TOD projects. In addition to that, the location relative to the main metropolitan city center has to be taken into account in order to ascertain current or potential TOD projects because of its significance on the travelers' behavior (Naess, 2011).

This research focuses on assessing regional TOD strategy by providing relevant accessibility measures at the local and regional scales. Two TOD projects are evaluated. The first one is assessed in a suburb of the main regional center; whereas the second one is assessed in a second-order peripheral center, which is basically matching the "downtown adjacent" and "town center" categories proposed by Leinberger (2009). According to the above-mentioned statements, the regional-scale effects of each project are, particularly, examined. Accordingly, the theoretical background leading to the schedule accessibility indicators is presented in Section 2. The method is described in section 3. The case study is introduced in Section 4. It tackles Nord-Pas de Calais which is a European region. ${ }^{2}$ The empirical results are presented and discussed in section 5 . The final section is the conclusion.

\footnotetext{
${ }^{1}$ The complete list of the useful indicators in measuring the TOD success includes Transit ridership, Density, Quality of streetscape design, Quantity of mixed-use structures, Pedestrian activity, Increase in property value, Public perception, Mode connections at the transit station, and Parking configuration (TRB, 2007).

${ }^{2}$ At $01 / 01 / 2016$, which is included in the time interval of this study, Nord Pas-de-Calais is merged in the larger Hauts de France region.
} 


\section{Theoretical backgrounds}

The accessibility indicators are usually categorized according to different methods of calculation, diverse types of collected data and different goals. The broadly used Geurs and van Wee (2004) classification defines four types of accessibility measures: infrastructure-based (the level of service of an infrastructure), location-based (the accessibility from a specific place), person-based (the accessibility for an individual) and utility-based (the economic benefit due to accessibility). The infrastructure-based indicators hardly permit the comparison between various areas or people. Besides, the location-based approaches are often preferred to others because they can be easily interpreted by stakeholders. In parallel, the person-based and utility-based indicators remain rare because they require significant data input and appropriate modeling tools (Benenson, Martens, Rofé, \& Kwartler, 2010; Neutens, Delafontaine, Scott, \& Demaeyer 2012). In addition to that, the conventional place-based accessibility measures encounter two major weaknesses with respect to public transport:

a. They fail to consider the accessibility fluctuations over time, notably within a period of one day. These fluctuations stem from several elements: the temporal rhythms of the activities that individuals are looking to get involved in, their personal and collective schedules, the opening hours of the facilities, and the public transport timetables. These limitations were claimed by Hägerstrand (1970) in the first place, which gave birth to the Time-Geography framework. Although the travel times are generally based on transit schedules and sometimes on in-vehicle measures, thresholds and average levels often tend to consider a constant velocity. For example, "given the lack of detailed schedule information, average travel speeds are typically assigned to the whole route, ignoring differences between different parts of the route" (Salonen \& Toivonen, 2013). Consequently, the accessibility fluctuation is imprecise over time. On the other hand, the temporal rhythms of activities, the personal schedules and the opening hours are taken into account only in a few specific research projects.

b. They aggregate measures at a coarse scale (municipality, county or neighborhood as stated in Benenson, Ben Elia, Rofé, \& Rosental, 2016) and roughly estimate the access, egress, transfer and waiting times. In fact, the spatial aggregation assumes that the accessibility is continuous inside the spatial unit. In addition to that, when the access, egress, transfer and waiting times are not ignored, they are not explicitly considered in the calculation. They are assumed to be constant relative to the headway time (Salonen \& Toivonen, 2013). Still, waiting and transfer times are critical for transit accessibility, as a minute of delay can turn into several hours of delay, notably in the regional public transport.

Among the person-based approach, the "activity-based" measures (Geurs \& Ritsema van Eck, 2001; McNally \& Rindt, 2007) address these hurdles based on the human viewpoint on accessibility. This conceptual framework assumes that travels are derived from individuals' wish to carry out some stationary activities (Vilhelmson, 1999). It aims at estimating these individuals' potential to achieve them. The virtues of the activity-based approaches in analyzing the land-use issues have, already, been demonstrated (Shiftan, 2008; van Wee, Bohte, Molin, Arentze, \& Liao, 2014; Liao, Arentze, Molin, Bohte, \& Timmermans, 2015). The indicators belong to the constraints-based approach when they are calculated on the basis of spatiotemporal constraints-system, which restricts the individuals' agenda (Neutens, Witlox, \& Demaeyer, 2007). For instance, the need to be back home before 8 p.m. to dine with family is a constraint to achieving various activities. These kinds of analyses are based on Time-Geography theoretical assets (Hägerstrand, 1985) leading to model accurate and realistic spatiotemporal environments wherein accessibility can be measured according to factors that depend on individuals (Lenntorp, 1978; Ohmori, Muromachi, Harata, \& Ohat, 1997; Wu \& Miller, 2001; Weber \& Kwan, 2003; Kim $\&$ Kwan, 2003). These methods have the advantage of disaggregating the accessibility measures according to selected amenities and segments of population. Actually, public transit timetables are required in 
order to assess how individuals can access to a set of urban opportunities vis-à-vis their temporal constraints. This "schedule accessibility" approach is consistent with the Time-Geography framework since it considers the management of individuals' schedule when accomplishing their daily activity programs. These assumptions are developed in various modeling approaches (Kwan, 1997, 1998) whereas contributions have previously pointed out the need of a timetable modeling in the transit studies, particularly railways (Kalsas \& Aase, 1997). Schedule accessibility models the transport service and not merely the transport supply, because schedules are considered in providing the demand insights, as stated by Rietveld and Bruinsma (1998).

\section{$3 \quad$ Method}

The employed method aims at providing an efficient and realistic calculation of accessibility within TOD strategy. However, measuring accessibility of individuals entails a survey that is neither possible to develop nor to commission at this scale. Hence, people's actual spatiotemporal movements are not considered in the current contribution. Rather, a potential is put forward. Therefore, schedule accessibility stands for an average individual with a potential behavior and an unknown agenda. In addition, this individual's dwelling is modeled as the nearest transit station. Consequently, the regional role of TOD strategy is assessed by schedule accessibility between stations that are mostly cities.

Furthermore, the transport service modeling allows the simulation of an activity and its associated time constraints. The most typical French working hours ${ }^{3}$ are used as time constraints in assessing the potential for commuting from/toward targeted TOD centers. Such indicators are developed in previous works (Baptiste \&, and L'Hostis, 2002; Conesa, 2012) but never in TOD analyses. Overall, in the matter of metropolitan-scale accessibility, eight indicators are provided for each prospected TOD area.

Let $O$ be a set of $n$ located origins $o_{i}$, T be the prospected TOD center, $T T_{i k}$ be the travel time from $o_{i}$ to $T$ according to a time-constraint $k . k$ can be a fixed departure time $(d t)$, a fixed arrival time $(a t)$, or a fixed time span $\left(t s\left[t s_{0}-t s_{1}\right]^{4}\right)$.

$o_{i} \in O ; 1 \leq i \leq n ; t s_{0}<t s_{1}$;

1) $N D T_{i}$ : Number of direct trains (without intermediate stops); if there is no direct train, it is the Number of direct routes (without interchange) between $T$ and $o_{i}^{5}$;

2) $S T T_{i}$ : Shortest travel time between $T$ and $o_{i} ; S T T_{i}=\min \left(T T_{i k}\right)$;

3) $A T T M_{i}$ : Average travel time during a morning peak-time between $T$ and $o_{i} ; A T T M_{i}=$ avg $\left(T T_{\text {its } 7 \mathrm{am}-9 \mathrm{am})}\right)$

4) $A T T E_{i}$ : Average travel time during an evening peak-time between $T$ and $o_{i} ; A T T E_{i}=$ avg $\left(T T_{i t 5[5 m-7 p m)}\right)$

5) $D T 8_{i}$ : Departure time from $o_{i}$ to reach $T$ before $8 \mathrm{am} ; D T 8_{i}=8: 00-T T_{\text {iatsam }}$;

6) DT9: Departure time from $o_{i}$ to reach $T$ before $9 \mathrm{am} ; D T 9_{i}=9: 00-T T_{\text {iat } 9 a m}$

7) $A T 5_{i}$ : Arrival time to $o_{i}$ from $T$, with a departure no earlier than $5 \mathrm{pm} ; A T 5_{i}=5: 00+T T_{\text {idt } 5 \mathrm{pm}}$

8) $A T \sigma_{i}$ : Arrival time to $o_{i}$ from $T$, with a departure no earlier than $6 \mathrm{pm} ; A T \sigma_{i}=6: 00+T T_{\text {idtopm }}$

As TOD exploits the local proximity to urban features, accessibility to urban functions provides insights on the potential of the TOD strategy at the local scale. Scott and Horner (2008) state that the studies on accessibility are overwhelmingly focusing on the access to job opportunities. In fact, local accessibility to other urban opportunities has seldom been studied. Accordingly, we brought forward

\footnotetext{
${ }^{3}$ Nowadays, these references seem to be less and less typical. Yet, ten years ago " $80 \%$ of the working time corresponded to the period between 9 a.m. and 7 p.m." (Chenu, 2002). As the "standard duration" for a workday is set to 8 hours (Rousseau, Gautier, \& Chapouthier, 2013), 8 a.m. and 9 a.m. are chosen as typical arrival times, and 5 p.m. and 6 p.m. are chosen as typical departure times.

${ }^{4}$ In a fixed timespan, only the paths running after $t s_{0}$ and arriving before $t s_{1}$ are taken into account.

${ }^{5}$ Unless it is specified, traveling between $T$ and $o i$ accounts for traveling back and forth between the two points.
} 
the accessibility indicators to a set of urban opportunities that do not include ubiquitous facilities like stores and restaurants. These amenities are not strictly comparable with each other. Still, they can be tallied according to a fixed timeframe. This measure gives an overview of local accessibility around a TOD station. Since the major role of walkability in the TOD achievements is stated, the walking times from the transit station to some selected opportunities are measured. Two indicators are put forward for each TOD area.

Let $A$ be a set of $m$ located amenities $a_{j}, T$ be the prospected TOD center, $P T T_{j}$ be the pedestrian travel time from $T$ to $a_{j}$

$a_{j} \in A ; 1 \leq j \leq m$;

9) $S A 15=\sum_{j=1}^{m}$ aj with $a_{j}=1$ if $P T T_{j} \leq 15$ minutes; $a_{j}=0$ if $P T T_{j}>15$ minutes;

10) $S A 10=\sum_{j=1}^{m} a_{j}$ with $a_{j}=1$ if $P T T_{j} \leq 10$ minutes; $a_{j}=0$ if $P T T_{j}>10$ minutes;

Two points can be discussed from these counts:

- The diversity of the accessible functions since diversity is one of the TOD's pillars;

- The scope of effect of these urban opportunities (region, urban area, city) since the regional role of TOD is tackled in this contribution. Those elements are not quantified in order to avoid a debatable weighting.

Actually, gathering and handling transit timetables are mandatory in implementing the aforementioned indicators and providing realistic accessibility measures with minute accuracy. Furthermore, the entire multimodal chain, and not merely railways, must be modeled when representing a door-to-door travel. That modeling process includes the local public transport timetables as well as the relevant pedestrian paths. By contrast, the bike paths and lanes are not modeled. Therefore, the exhaustive public transport service is implemented in a transportation-oriented GIS (MapNod). A directed p-graph models the whole network. The nodes represent the transit stops and the urban opportunities. The edges represent the links. The $p$-graph is composed with several edges between two nodes that correspond to various routes at separate times for the same origin/destination pair. This specification enables the modeling of each route from midnight to $11: 59$ p.m. during a typical weekday, such as a Tuesday of November. The transfer times ${ }^{6}$ yield complete trip chains. In addition, when two transit stops are close to each other, the transfer time is measured by the stopwatch rather than GIS-based computations. The access, egress and walking times between the transit stops and the amenities are, also, calculated by the stopwatch. However, this method cannot be employed in each transit station. Consequently, it focuses on the main rail stations.

The current application partly addresses conventional place-based measures limitations that are pointed out in section 2. First, gathering and handling complete transit timetables allow the measurement of the public transport accessibility fluctuations over a day span. Conversely, data about individual and opening hours are not considered, whereas the activity temporal rhythms are simplified. Second, schedule accessibility is measured based on a specific place and not on individuals, but there is no spatial aggregation that assumes continuous accessibility. Furthermore, the access, egress, waiting and transfer times are either based on timetables or stopwatch timing, at least for the main stations. The suggested indicators remain location-based measures, with the specificity of incorporating timetables. ${ }^{7}$

The indicators introduced in the section 1 are based on the $T T_{i k}$ measure, which stands for travel time according to constraints that are previously explained. These travel times are calculated based on the shortest path provided by a tailored version of the Dijkstra algorithm. This specific version is adapted in both the scheduled and non-scheduled travel modes. For instance, walking is a non-scheduled travel mode. Moreover, since the time-constraints can be either a departure time or an arrival time, the algo-

\footnotetext{
${ }^{6}$ See the appendix.

${ }^{7}$ Further details about the schedule accessibility approach are available in Conesa and L'Hostis (2011).
} 
rithm must be reversible, which means able to run forward and backward (Daganzo, 1998).

\section{$4 \quad$ Case study}

To illustrate how the schedule accessibility indicators can shed light on TOD, especially on the regional implications of TOD strategy in Europe, a case study is elaborated.

\subsection{Two scenarios to assess a regional TOD strategy}

Nord Pas-de-Calais is one of the densest French regions with more than 6 million inhabitants in an area of $12,400 \mathrm{~km}^{2}$. The strong attractiveness of Lille is one of the key features that define the regional planning policies besides the disparities that are endured, notably, by the former mining area (Lo Feudo, 2014). The efficiency of the well-organized regional rail system is regarded as a major driver in overtaking those disparities and developing the region (Baptiste \& L'Hostis, 2002; Menerault et al., 2006; Lo Feudo, 2014).

Two TOD scenarios are presented in the assessment of the TOD strategy. These scenarios are committed to the improvement of the transport services, but not the land use. This study is complementary to the research done by Lo Feudo (2014). He employs an aggregated 4-step model in simulating the land-use changes when tackling the TOD strategy in this region. According to the aforementioned challenges in Nord Pas-de-Calais, the following two scenarios are presented:

1. Lille Saint-Sauveur is a former freight train station located in the southern districts of Lille. During the study, it has been a deserted brownfield. The "tram-train," a new transit service, is the mainstay of the urban planning strategy that is developed in Menerault et al. (2006). It maintains the speed and reduces the distance between stations thanks to short acceleration/ deceleration times. This technical asset enables the access to a set of suburban towns (Figure 1) from the south of Lille. The connection between the city center and this train station relies on the VAL. ${ }^{8}$ Although the tram-train specific virtue is to fill underused rail lines, an increase in the transit capacity is simulated. That virtually corresponds to treble or quadruple the number of tracks in the relevant rail lines.

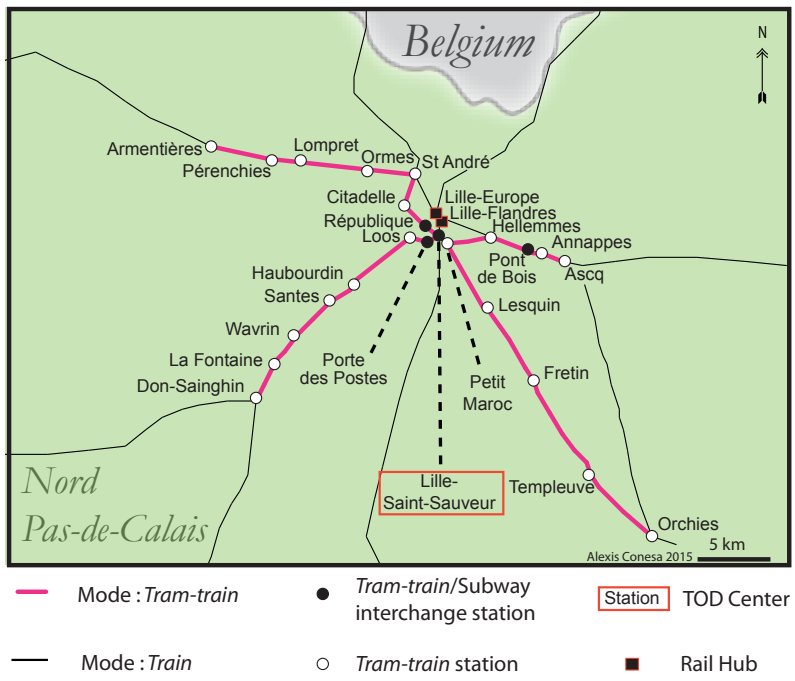

Figure 1: Scenario of a suburban tram-train station in Lille Saint-Sauveur: Transportation system

\footnotetext{
${ }^{8}$ VAL stands for Véhicule Automatique Léger, which means Light Automatic Vehicle. It is a subway-like transit system used in the Lille metropolitan area.
} 
This scenario 9 is considered ambitious. It appears to be in line with the TOD prescripts, which are the urban consolidation by an infill development, the containment of the urban sprawl, and the enhancement of a mixed land use around the train station (Figure 2). This scenario stands for the "downtown-adjacent" TOD center.

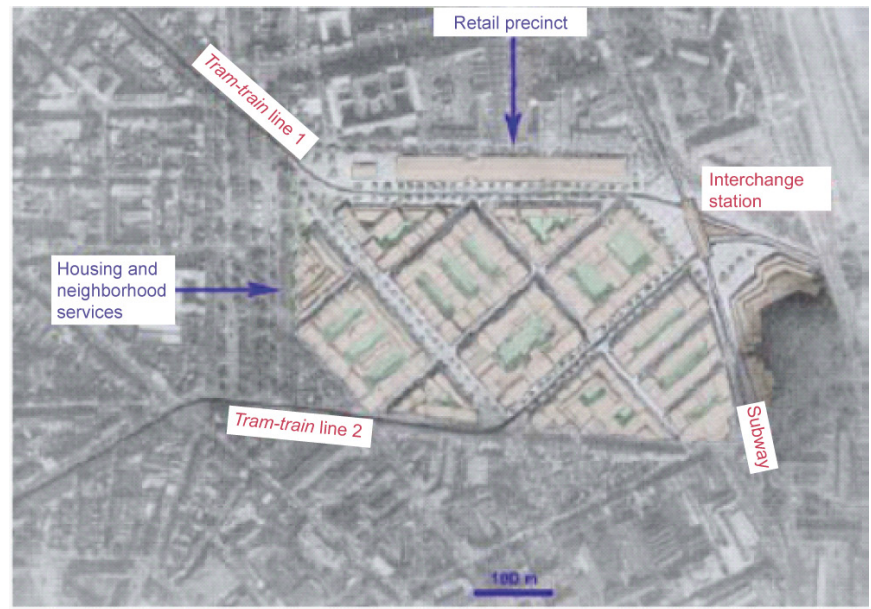

Figure 2: Scenario of a suburban tram-train station in Lille Saint-Sauveur: Urban project (Menerault et al., 2006 p. 82, personal translation)

2. The disparities between Lille Metropolitan Area (LMA) and the former coalfields area are one of the main issues at stake in Nord Pas-de-Calais. They result from socio-economic origin but exacerbated by unequal accessibility. In fact, a transfer at Lille is required in most transit trips between the former mining area centers; Lens, Valenciennes, Béthune and Douai are the four main cities of this conurbation. It reinforces the status of the regional hub (Conesa, 2010). The weakness of the transit service hinders the potential development of the east-west trips, whereas a more balanced urban framework is targeted (SRADDT, 2012). Hence, we bring forward a reorganization of the train timetables that includes the conception of new Valenciennes-DouaiLens-Béthune routes in creating an incentive for a more polycentric plan (Figure 3). The trains are reorganized to fulfill the aforementioned route without any interchange several times a day. However, no train track is added. This restructuration impacts a large part of the regional railway timetables. This scenario ${ }^{10}$ is money-saving.

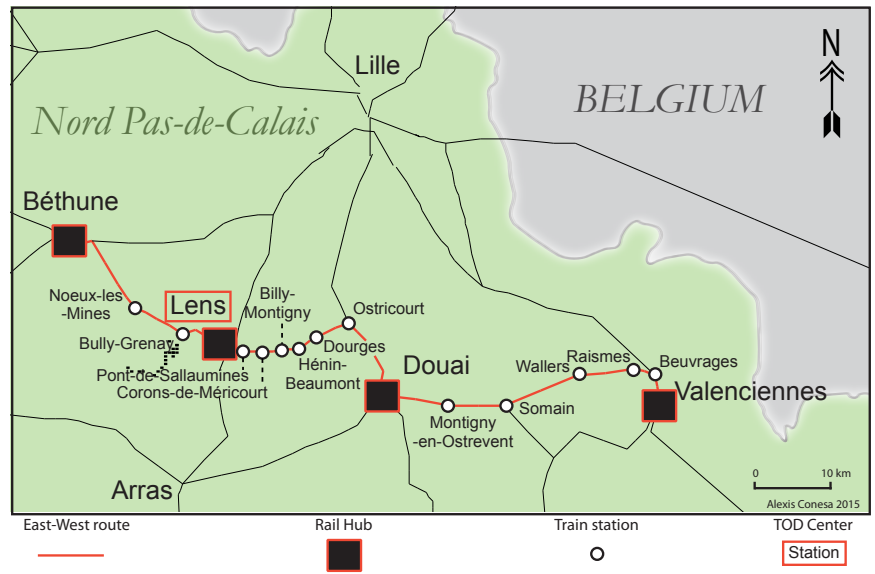

Figure 3: Scenario of east-west route in the former mining area

\footnotetext{
${ }^{9}$ Further explanations of the theoretical, technical, and political aspects of this scenario are available in Menerault et al. (2006).

${ }^{10}$ Further explanations of the theoretical, technical, or even political aspects of this scenario are available in Conesa (2010).
} 
With respect to the current planning policies carried out in Nord Pas-de-Calais, a TOD center is placed around the train station in Lens. ${ }^{11}$ Therefore, this scenario raises the question of a TOD positioning in a second-order center.

\subsection{Data implementation}

Automated methods scraping Die Bahn website help to retrieve rail timetables (Conesa \& Leysens, 2015). As well, agreements with the relevant bodies in charge of transport permit to gather the local services. The complete rail services and the simplified local services (Nord and Pas-de-Calais coaches, ${ }^{12}$ LMA urban bus ${ }^{13}$ LMA VAL, former mining area bus and Valenciennes streetcar) ${ }^{14}$ are modeled in a regional $p$-graph that is made up of 1,378 nodes and 62,442 edges. This graph includes both scheduled (rail, coach and bus) and non-scheduled (VAL, streetcar, walking) travel modes. Both the added transport service (scenario 1) and transport service reorganization (scenario 2) are in line with the network characteristics (vehicle properties, train paths, crossings at grade, etc.).

The previously introduced accessibility indicators are measured for every transit station in the region. Yet, for more readability, the results are displayed for only the 14 major Nord Pas-de-Calais cities. The nodes that correspond to these cities are the nearest transit stations to the city center. However, they are not necessarily the main train stations. This methodological choice can be considered as more realistic as far as commuting is concerned. The potential dwellings are more likely located in the city center than around the train station (see appendix ${ }^{15}$ ).

The maps display the results for every node in the graph for the selected indicators.

\section{$5 \quad$ Results and discussion}

The results of the regional accessibility analysis consist of measuring the differences between the original situations (T0) and the scenarios (T1). Tables 1 and 2 present the changes in minutes according to [T0 T1] (except $N D T_{i}$ which corresponds to the number of trains/routes). A map that exemplifies the results is displayed for each scenario (based on AT6 in scenario 1 and DT8 on scenario 2). Contrariwise, for the pedestrian accessibility, the maps display only the results for the original situation.

\subsection{Lille Saint-Sauveur scenario}

Table 1 shows that the fastest travel times and the average travel times during the peak-time are improved for all directions, specifically Béthune, Lens, and Ascq, which is the ultimate station of the simulated tram-train line.

\footnotetext{
${ }^{11}$ The Nord Pas-de-Calais regional bodies fostered the placement of the Louvre museum annex in Lens.

${ }^{12}$ Nord and Pas-de-Calais were the two départements of the Nord Pas-de-Calais region. In France, the départements were in charge of the coach services until 01/01/2017.

13 "TADAO" is the network of Syndicat mixte des transports Artois-Gohelle, which is the local body in charge of transport in the urban area including Lens and Béthune.

${ }^{14}$ VAL and streetcars frequency is about a minute in the rush hours. They are, therefore, considered as continuous services. This means that there is no waiting time at the stations although the travel times between two stations are based on the timetables.

${ }^{15}$ In the case of Lille, where two main train stations exist (Lille-Flandres and Lille-Europe), the more accessible station is taken into account according to the measure.

${ }^{16}$ In the case of Lens, the TOD center is located in the train station in the second scenario whereas the Saint-Léger coach station stands for the city center in the first scenario appraisal.
} 
Table 1: Accessibility changes for the 14 main cities in Lille Saint-Sauveur scenario

\begin{tabular}{|l|c|c|c|c|}
\hline \multicolumn{6}{|l|}{ Changes in accessibility from Lille Saint-Sauveur } \\
\hline FROM : & $S T T$ & $A T T M$ & $A T T E$ & $N D T$ \\
\hline Lille & 3 & 1 & 1 & 0 \\
\hline Cambrai & 3 & 0 & 1 & 0 \\
\hline Maubeuge & 2 & 3 & 4 & 0 \\
\hline Douai & 3 & 1 & 0 & 0 \\
\hline Béthune & 15 & 2 & 3 & 0 \\
\hline Arras & 4 & 0 & 0 & 0 \\
\hline Dunkirk & 3 & 4 & 5 & 0 \\
\hline Lens & 14 & 3 & 2 & 0 \\
\hline Valenciennes & 2 & 2 & 6 & 0 \\
\hline Calais & 3 & 1 & 3 & 0 \\
\hline Boulogne & 3 & 4 & 5 & 0 \\
\hline Tourcoing & 6 & 2 & 2 & 0 \\
\hline Armentières & 3 & 5 & 4 & 41 \\
\hline Ascq & 16 & 17 & 17 & 67 \\
\hline
\end{tabular}

\begin{tabular}{|l|c|c|c|c|}
\hline \multicolumn{6}{|c|}{ Changes in accessibility to Lille Saint-Sauveur } \\
\hline TO : & $S T T$ & $A T T M$ & ATTE & NDT \\
\hline Lille & 3 & 1 & 1 & 0 \\
\hline Cambrai & 3 & 1 & 1 & 0 \\
\hline Maubeuge & 2 & 3 & 4 & 0 \\
\hline Douai & 3 & 1 & 1 & 0 \\
\hline Béthune & 15 & 4 & 2 & 0 \\
\hline Arras & 4 & 1 & 1 & 0 \\
\hline Dunkirk & 3 & 2 & 1 & 0 \\
\hline Lens & 14 & 4 & 3 & 0 \\
\hline Valenciennes & 2 & 4 & 2 & 0 \\
\hline Calais & 3 & 2 & 2 & 0 \\
\hline Boulogne & 3 & 4 & 5 & 0 \\
\hline Tourcoing & 6 & 2 & 2 & 0 \\
\hline Armentières & 3 & 6 & 6 & 41 \\
\hline Ascq & 13 & 16 & 20 & 67 \\
\hline
\end{tabular}

\begin{tabular}{|l|c|c|c|c|}
\hline \multicolumn{6}{|l|}{ Changes in accessibility with Lille Saint-Sauveur } \\
\hline WITH : & $D T 8$ & $D T 9$ & $A T 5$ & $A T 6$ \\
\hline Lille & 0 & 1 & 6 & 6 \\
\hline Cambrai & 0 & 0 & 0 & 0 \\
\hline Maubeuge & 0 & 0 & 0 & 0 \\
\hline Douai & 0 & 0 & 0 & 0 \\
\hline Béthune & 0 & 0 & 0 & 0 \\
\hline Arras & 0 & 0 & 0 & 0 \\
\hline Dunkirk & 0 & 0 & 0 & 0 \\
\hline Lens & 0 & 0 & 0 & 0 \\
\hline Valenciennes & 0 & 0 & 0 & 3 \\
\hline Calais & 42 & 0 & 0 & 0 \\
\hline Boulogne & 0 & 0 & 0 & 0 \\
\hline Tourcoing & 0 & 0 & 0 & 0 \\
\hline Armentières & 0 & 0 & 0 & 0 \\
\hline Ascq & 30 & 22 & 0 & 33 \\
\hline
\end{tabular}

Figure 4 shows that the accessibility spills over the tram-train operating area (which matches LMA), especially in the southern east of the region. In this example, new interchange opportunities are provided thanks to an ahead-of-time arrival of the train to Orchies. It would be possible to take the bus $\left(\mathrm{n}^{\circ} 25\right)$ at Orchies and be back to various places next to Douai ${ }^{17}$ in the evening. The same effects occur in Valenciennes with a transfer to the train going to the southern east.

However, the new service does not impact most of the region. With the exception of Ascq and to a lesser extent Calais, no regional center has improved its schedule accessibility with Lille Saint-Sauveur. We assume that these results are due to the fact that the current train service toward Lille is, already, quite efficient. The main gain from the tram-train project might not be the speed but the frequency and the fineness of the transit service.

\footnotetext{
${ }^{17}$ Douai central station is not affected, as the route is different.
} 


\section{Testing new transit service, departure from Lille-Saint-Sauveur from 6 P.M.}

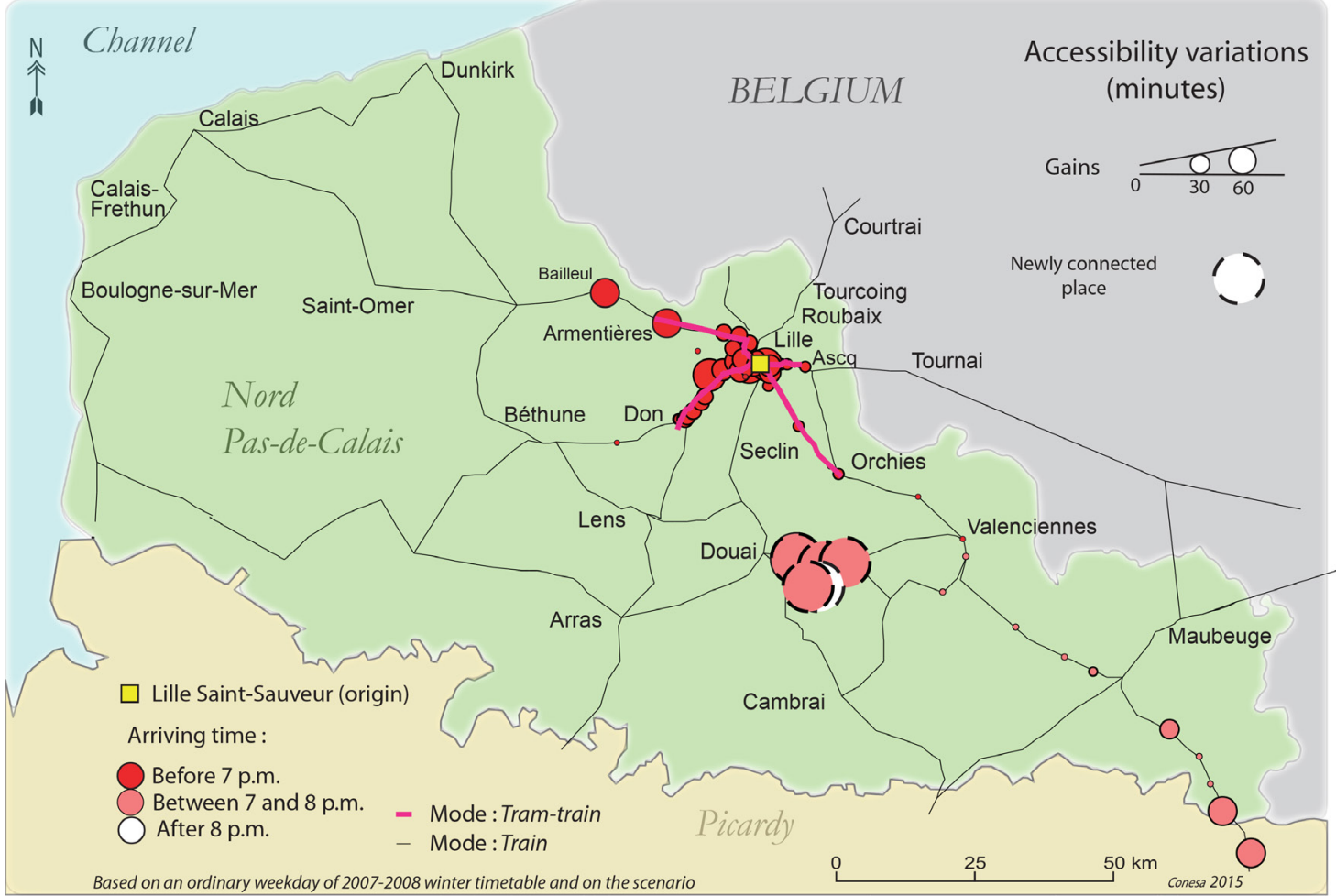

Figure 4: Regional-scale accessibility gains thanks to the tram-train project

Regarding the local accessibility, $S A 15=9, S A 10=7$ (Figure 5). The economical, administrative, leisure, and educational facilities are reachable. Moreover, two urban opportunities of regional importance are comprised in the 10-minute frame (Euralille 2 office buildings and the Region Hall).

To sum up, the Lille Saint-Sauveur scenario demonstrates that a downtown-adjacent district is likely to host an effective TOD center. Thanks to its location, which is next to the main city-region center, the proposed station combines good levels of accessibility both at coarser and finer scales. Nonetheless, at the regional level, the new transport service worsens the aforementioned disparities since it does not have a clear impact beyond LMA. 


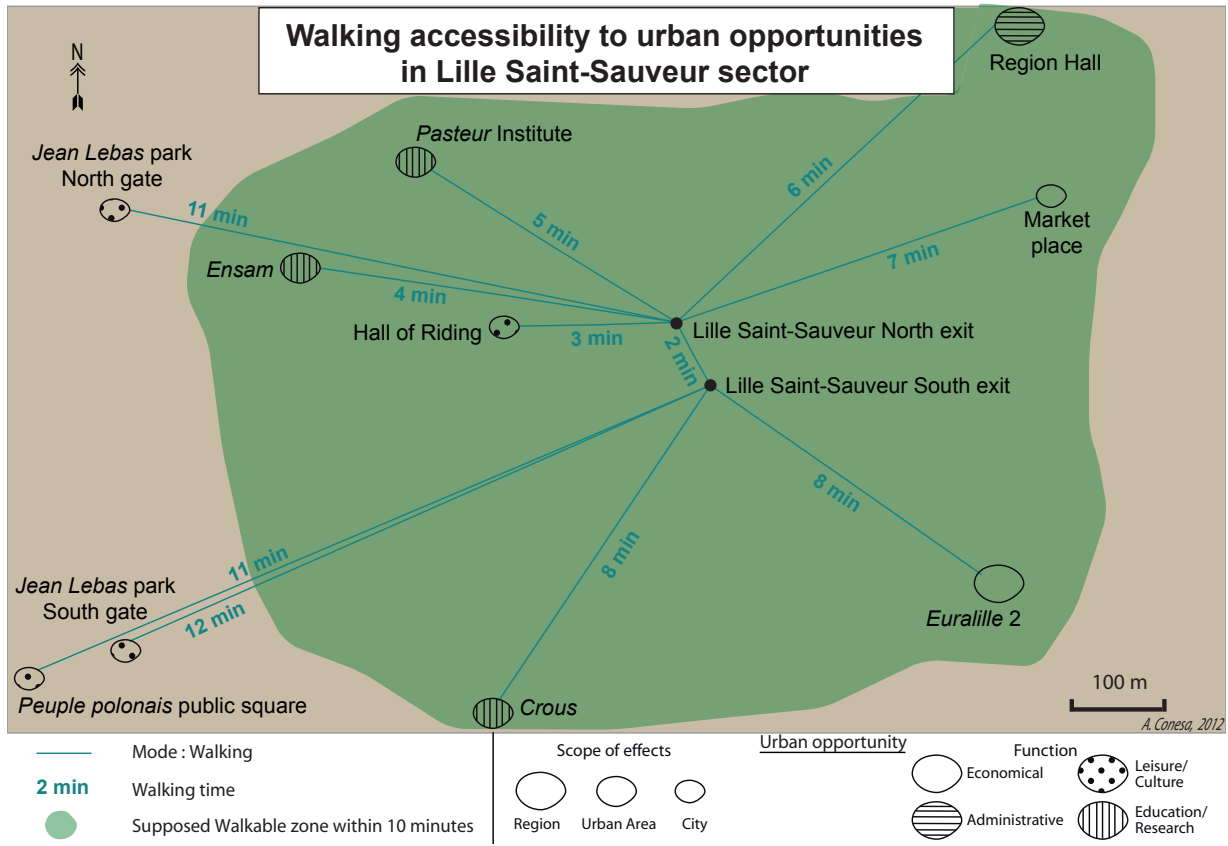

Figure 5: Lille Saint-Sauveur, a quite walkable place

\subsection{Lens scenario}

Many limitations confront the assessment of Lens scenario. In fact, most of the indicators are not absolutely meaningful. ${ }^{18}$ Besides, an overview of the results shows that time losses are more numerous than time gains (Table 2). Furthermore, a traveling time saving between two cities can be a traveling time loss in either the way back or by a different time. The following observations are got from Table $2 \mathrm{a}$ and $2 \mathrm{~b}$ :

i. Virtually every schedule accessibility variation occurs in an arrival to Lens at 8 a.m.;

ii. The accessibility is, generally, improved in the evenings and impaired in the mornings, particularly toward Lens;

iii. On the whole, all the cities that rely on a transfer at Lille to reach Lens are less accessible;

iv. Valenciennes-Lens and Lens-Maubeuge links are improved in the evenings. Indeed, they are allowing a significant time saving from Lens to the southern east side of the region.

\footnotetext{
${ }^{18}$ Douai central station is not affected, as the route is different.
} 
Table 2: Accessibility changes for the 13 main cities in Lens scenario

\begin{tabular}{|l|c|c|c|c|}
\hline \multicolumn{5}{|c|}{ Changes in accessibility from Lens } \\
\hline FROM : & $S T T$ & $A T T M$ & $A T T E$ & $N D T$ \\
\hline Lille & 0 & 0 & 1 & -10 \\
\hline Cambrai & 0 & 0 & 1 & 0 \\
\hline Maubeuge & 0 & 0 & 4 & 0 \\
\hline Douai & 0 & -5 & 0 & 3 \\
\hline Béthune & 0 & -11 & 0 & -1 \\
\hline Arras & 0 & 0 & 0 & 0 \\
\hline Dunkirk & 0 & 1 & -1 & 0 \\
\hline Valenciennes & 0 & -1 & 15 & 0 \\
\hline Calais & 0 & -1 & 7 & 0 \\
\hline Boulogne & 0 & 0 & 15 & 0 \\
\hline Tourcoing & 0 & -9 & 9 & 0 \\
\hline Armentières & 0 & -2 & 0 & 0 \\
\hline Ascq & 0 & -3 & -17 & 0 \\
\hline
\end{tabular}

\begin{tabular}{|l|c|c|c|c|}
\hline \multicolumn{5}{|c|}{ Changes in accessibility to Lens } \\
\hline TO : & $S T T$ & $A T T M$ & $A T T E$ & $N D T$ \\
\hline Lille & 0 & -4 & -2 & -9 \\
\hline Cambrai & 0 & 4 & 1 & 0 \\
\hline Maubeuge & 0 & -2 & 15 & 0 \\
\hline Douai & 0 & 5 & -1 & 5 \\
\hline Béthune & 0 & 2 & 0 & 0 \\
\hline Arras & 0 & -13 & 0 & 0 \\
\hline Dunkirk & 0 & 1 & 0 & 0 \\
\hline Valenciennes & 0 & 4 & -6 & 0 \\
\hline Calais & 0 & -4 & 1 & 0 \\
\hline Boulogne & 0 & -4 & -2 & 0 \\
\hline Tourcoing & 0 & -3 & -3 & 0 \\
\hline Armentières & 0 & -5 & -1 & 0 \\
\hline Ascq & 0 & -2 & -4 & 0 \\
\hline
\end{tabular}

\begin{tabular}{|l|c|c|c|c|}
\hline \multicolumn{5}{|c|}{ Changes in accessibility with Lens } \\
\hline WITH : & $D T 8$ & $D T 9$ & $A T 5$ & $A T 6$ \\
\hline Lille & 0 & 0 & 0 & 0 \\
\hline Cambrai & 30 & 0 & 0 & 0 \\
\hline Maubeuge & 39 & 0 & 0 & 0 \\
\hline Douai & 0 & 0 & 0 & 0 \\
\hline Béthune & Disconnection & 0 & 0 & 0 \\
\hline Arras & 0 & 0 & 0 & 0 \\
\hline Dunkirk & -39 & 0 & 0 & 0 \\
\hline Valenciennes & 41 & 0 & 0 & 9 \\
\hline Calais & 0 & 0 & 0 & 0 \\
\hline Boulogne & -60 & 0 & 0 & 0 \\
\hline Tourcoing & 0 & 0 & 0 & 0 \\
\hline Armentières & 0 & 0 & 0 & 0 \\
\hline Ascq & 0 & 0 & 0 & 0 \\
\hline
\end{tabular}

Table 2c shows that when the train frequency is already high, the reorganization has virtually no effects. It also points out that when the train frequency is poor (for example, before 7 a.m.), the reorganization improves the links with the former mining area cities (chiefly Valenciennes, Cambrai, Béthune, and Maubeuge) and deteriorates the links to the coastal cities (Boulogne-sur-mer and Dunkirk). The reorganization creates a gap-filler service in the former mining area. The drawback is the loss of connection with all the western side of the region (Figure 6). 
Testing change in rail service, arrival to Lens before 8 A.M.

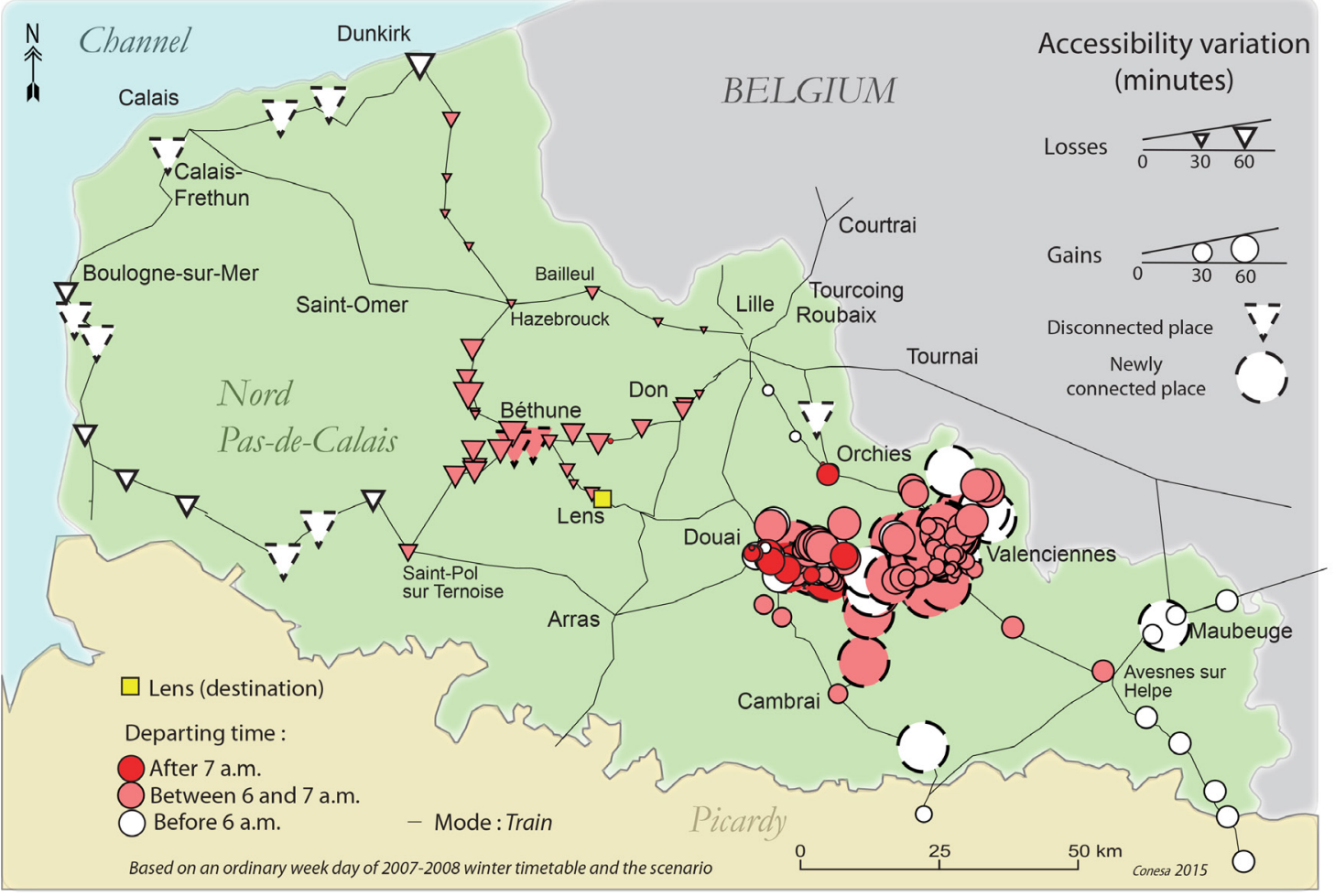

Figure 6: Mixed results concerning rail service reorganization

In addition to the figures, the drawing and the content of the shortest paths can help in analyzing and interpreting the results. Figure 7 shows a gain in the commuting potential between Lens and Valenciennes.

Shortest path from Valenciennes to Lens for an arrival before 8 A.M.

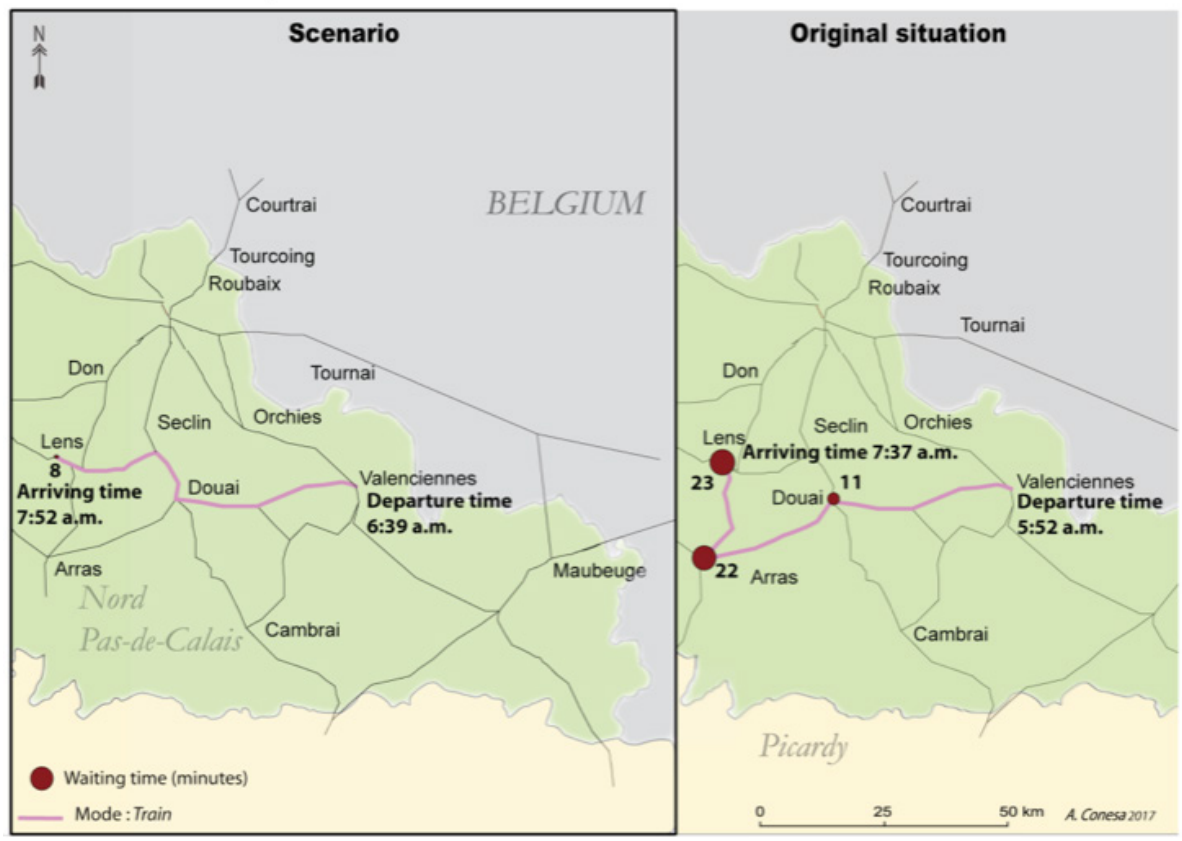

Figure 7: Gain of directness in a periphery-periphery link thanks to the rail service reorganization 
Regarding the neighborhood-scale accessibility, $S A 15=4, S A 10=4$ (Figure 8). Unlike the first scenario, neither the economical nor the educational facilities are reachable. Furthermore, there is a lack of a regional-scale facility. Therefore, it is contended that the main station of a second-order center provides a poorer walkable accessibility to the urban opportunities than a downtown-adjacent station that is located in the main metropolitan center.

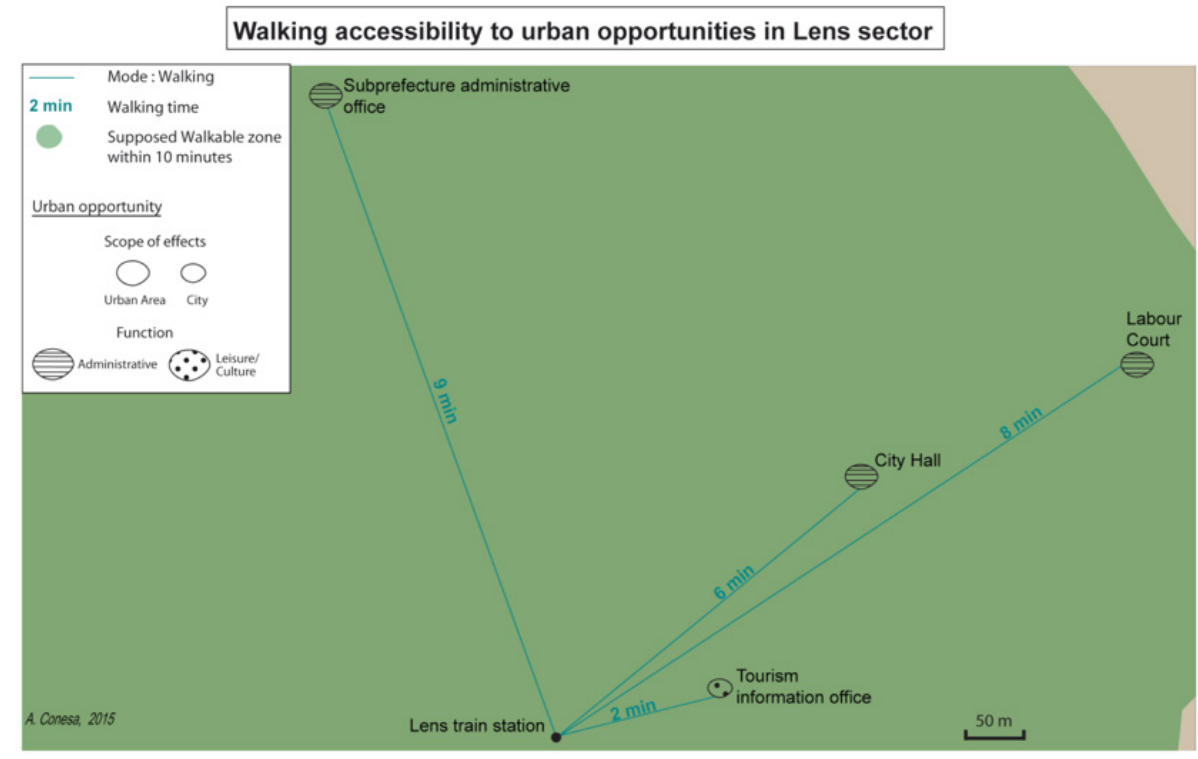

Figure 8: Lens train station and its one-direction walkable radius

These results illustrate the complexity of the timetables entanglement and the consequential difficulty to reorganize the regional services. In the case of Lens, it is concluded that TOD may encounter some hurdles in a second-order center. In fact, the scenario shows that a potential to enhance the central role of Lens within the former mining area is possible. It also highlights an accessibility improvement toward the southern east side of the region, which is the poorest and the least accessible. Moreover, this scenario is money-saving and not efficient enough. Probably a more expensive planning operation could be mandatory to improve it. Still, the regional impact of a TOD center in Lens remains highly questionable since this project is unlikely to overcome the regional disparities. Perhaps focusing on an intermediate scale and ensuring a good accessibility to Lens within the former mining area could be more realistic because of the small extent of potential TOD in Lens. The following subsection develops the assessment of this intermediate scale accessibility.

\subsection{Lens intermediate accessibility analysis}

To support the Lens transit station in fulfilling an effective local role, we brought forward an intermediate travel mode. This is consistent with the Feeder-Distributor-Circulator (FDC) concept, which is introduced in Schneider (2012). A FDC system feeds the mass-transit stations and contains the urban sprawl at the intermediate scale, with respect to the E-TOD framework that tends to spread the TOD strategy between the rail stations. In this study, we assume that the FDC system is embodied by:

a. The TADAO bus (cf. section 4);

b. The Pas-de-Calais coach. 
The relevant urban opportunities, at this scale, are selected as follows:

i. The surrounding town centers (city halls);

ii. The urban opportunities in Lens.

No new transit service has been mocked up. Therefore, the maps and tables display the results for the original situation only. The DT8i, DT9i, AT5i and AT6i indicators introduced in section 3 are reused. The overall study of these four indicators shed light on the way the FDC system links the projected TOD to the surrounding towns and the urban opportunities. The results, in this section, are standing for the departure and arrival times from Lens station to a given urban opportunity or town. The, the diversity and scope of effects of those urban opportunities can be analyzed.

The results point out that two urban area scale opportunities are accessible in less than 15 minutes. ${ }^{19}$ Furthermore, some educational, administrative, health and recreational facilities can be reached in less than 30 minutes. In addition, half a dozen of the surrounding towns are accessible within an hour (Figure 9, Table 3). Still, the Louvre bis, which is the only amenity of regional importance, is not accessible at the time of the study. This major project is assumed to deeply change the local transit schedule, though.

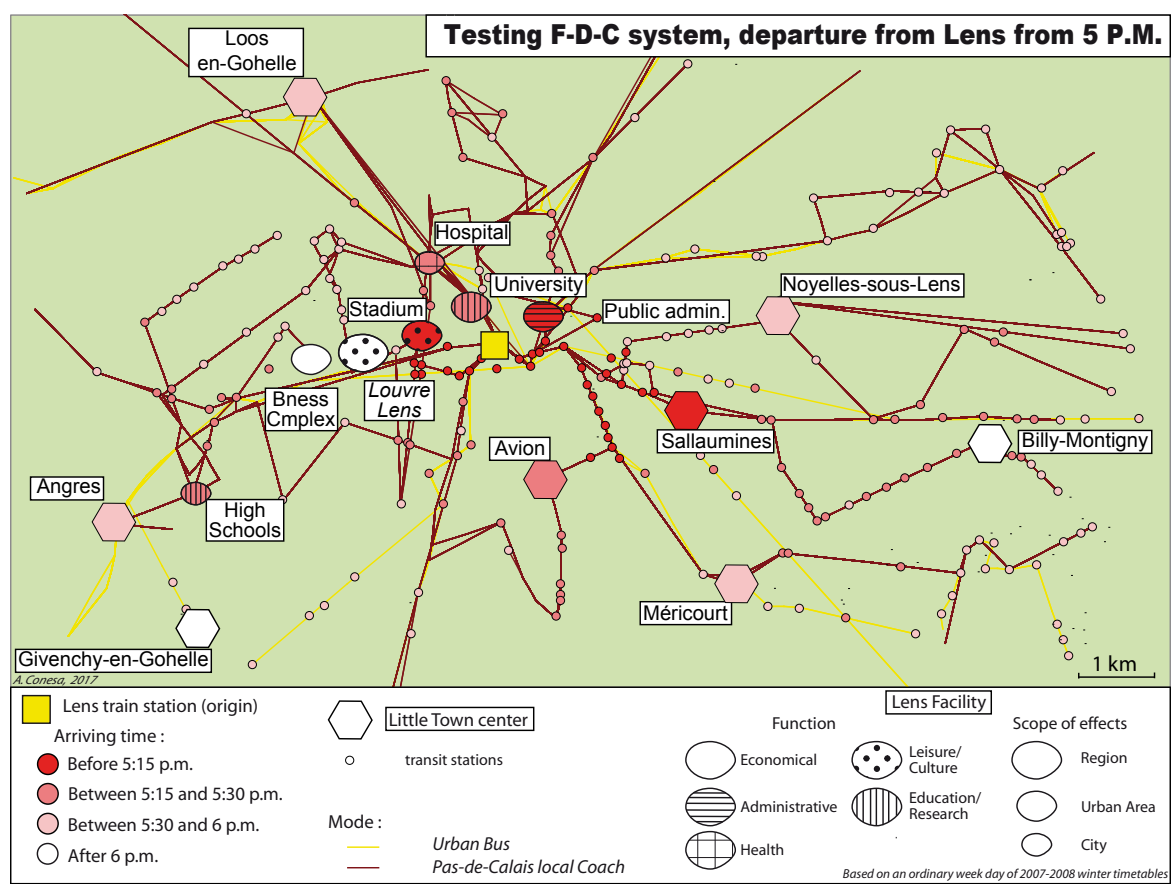

Figure 9: Intermediate accessibility around Lens transit station

\footnotetext{
${ }^{19}$ They consist of the famous Bollaert stadium where the very popular soccer club RC Lens plays and the Saint-Léger square which hosts the city hall as well as other local government bodies.
} 
Table 3: Lens area intermediate services analysis

\begin{tabular}{|c|c|c|c|c|c|c|}
\hline FACILITIES & UDT8 & UDT9 & UAT5 & UAT6 & Scope of Effects & Function \\
\hline Louvre-Lens museum & $6: 32$ & 8:01 & 6:01 & $7: 23$ & Region & Leisure/Culture \\
\hline Cap liévin business complex & 0 & 0 & $6: 30$ & $7: 23$ & Urban area & Economical \\
\hline Saint-Léger public administrations & $7: 52$ & $8: 52$ & 5:08 & $6: 12$ & Urban area & Administrative \\
\hline Bollaert Stadium & $6: 52$ & $8: 48$ & $5: 13$ & $6: 10$ & Urban area & Leisure/Culture \\
\hline University & $7: 44$ & $8: 44$ & $5: 19$ & $6: 19$ & Urban area & Educational/Research \\
\hline Hospital & $7: 44$ & $8: 44$ & $5: 19$ & $6: 19$ & City & Health \\
\hline High Schools & $7: 30$ & $8: 27$ & $5: 30$ & $6: 30$ & \multirow[t]{10}{*}{ City } & Educational/Research \\
\hline \multicolumn{5}{|l|}{ TOWNS } & & \\
\hline Billy-Montigny city hall & $7: 17$ & $8: 17$ & $6: 22$ & 7:09 & & \\
\hline Avion city hall & $7: 44$ & $8: 44$ & $5: 30$ & $6: 22$ & & \\
\hline Sallaumines city hall & $7: 33$ & $8: 33$ & $5: 14$ & $6: 14$ & & \\
\hline Angres city hall & $7: 11$ & 8:03 & $5: 57$ & $6: 57$ & & \\
\hline Givenchy-en-Gohelle city hall & 0 & 0 & $6: 35$ & $6: 35$ & & \\
\hline Loos-en-Gohelle city hall & $6: 32$ & $7: 58$ & $5: 50$ & $6: 58$ & & \\
\hline Méricourt city hall & 7:04 & 8:04 & $5: 35$ & $6: 42$ & & \\
\hline Noyelles-sous-Lens city hall & $6: 59$ & $8: 18$ & $5: 57$ & $6: 44$ & & \\
\hline
\end{tabular}

This investigation suggests that a second-order TOD center can be implemented in Lens with an appropriate investment. Actually, the intermediate scale service gives access to urban area scale opportunities and educational functions that are not within the walkable radius. In fact, the underlying role of Lens for its satellite towns could be reinforced. Therefore, the disparity problems could be alleviated at the regional scale. Nevertheless, it remains uncertain that Lens could act as a counterweight to Lille. The placement of an international-scale project (namely, the Louvre bis) in the former mining area is a strong political act which could lead to an ambitious transit enhancement policy. ${ }^{20}$ However, it is highlighted, in the previous section, that the railways schedule reorganization is quite complex because of the management of disparities. At the local scale, the effectiveness of coaches and buses within the urban area of Lens is not able to match the underground rail system efficiency within LMA. This failure raises the implementation issue of a mass-transit system in a peripheral urban area. In fact, it requires very strong initiatives. All the tramway projects that fail over the last decade within the same former mining area can witness for such difficulty. This result fits the output of previous works, which applied different methods to the same region. ${ }^{21}$

\section{Conclusion}

The embedding of transport and urban planning features is a major global concern (Cervero, 2013). Therefore, there is a great deal of interest in TOD even though accessibility, which is one of its key factors, is seldom accurately assessed. Correspondingly, this study aims at assessing a TOD strategy in a European metropolitan region through proposing multiscale accessibility indicators. Complete timetables of the Nord Pas-de-Calais regional railway services are gathered using a transportation-oriented GIS.

\footnotetext{
${ }^{20}$ Since the museum has opened its doors in December 2012, an appraisal of the current situation ought to be made in future researches.

21 "These results show that TOD effects are more evident in areas that already present good levels of attractiveness and of economic dynamism, while are less pronounced in areas with lower transport and residential basic demand and activities density" (Lo Feudo, 2014).
} 
They help in providing deeper insights on the potential impacts of various TOD centers, at the regional scale. The average travel times and, to a lesser extent, the shortest times are not always useful. It is not the case of the indicators that are related to schedule accessibility (DT8, DT9, AT5, and AT6). Therefore, it is recommended to potential practitioners to use this kind of indicators in their TOD prospective study. Indeed, they allow them to tackle unwanted accessibility results. Opposite value directions between those indicators may draw the attention of decisionmakers on the timetables' complexity and make them test various solutions before taking any decision. Moreover, the current walking and biking indicators cannot be developed at a large scale because the stopwatch method is inconvenient. In addition, travel demand data would help to reinforce this human-based accessibility approach and to particularize the indicators according to any observed behavior.

Despite these limitations, the case study points out two main findings on the implementation of TOD strategy in a metropolitan region. On one hand, a TOD center is likely to enhance an intermediate scale urban centrality, such as a neighborhood within its metropolitan area regarding a downtownadjacent TOD (e.g., Lille Saint-Sauveur within LMA) or a city within its urban area regarding a secondorder TOD (e.g., Lens within former mining area). On the other hand, the local modifications can alter the regional structures because of the railway schedules complexity. The regional impact of the transit service changes remains uncertain unless a voluntary and expensive policy that supplies a new infrastructure development is put in place (the Lille Saint-Sauveur scenario). Thus, the management of the accessibility unevenness is difficult at the regional level. Nord Pas-de-Calais is a densely populated region and relies on an already efficient transit service. Accordingly, these findings can be extended to other former industrial areas in western Europe. Actually, it is proved that the implementation of a TOD spot beyond the main metropolitan center is difficult anywhere, as, for example, in the outskirt of Shanghai. ${ }^{22}$ Hence, the following recommendations assume an international generalization.

First, TOD policies should include several spots because a full-fledged regional strategy requires a concerted action of planning and a dissemination of good practices. A TOD center located in the main regional center must be accompanied by a more peripheral one, whenever possible, to alleviate the unavoidable disparities. Furthermore, local and intermediate scale accessibilities must not be neglected. Indeed, although TOD is often associated with the mass-transit systems, buses, coaches, biking, and walking allow policymakers to improve the accessibility to urban opportunities and towns at an affordable cost. The intermediate scale role of a TOD center is thereby reinforced even though its regional role remains hypothetical. Such limitation is the output of the reorganization of the rail regional system. It enhances the usefulness of the schedule modeling. Actually, the results from this contribution give better insights in preventing unwanted regional effects. ${ }^{23}$

To sum up, the success of TOD projects relies on the proper matching between a public transit service and a set of urban opportunities. This statement paves the way for more complete TOD assessments. Thus, further researches should combine various methods in addressing these crucial issues. For example, the activity-based approach may be coupled with a spatiotemporal land-use modeling that explicitly considers the differences between the urban opportunities. This combination would include real or simulated land uses as well as urban opportunities operating hours (Fosset et al., 2016). Consequently, it could provide more accurate and relevant measures, especially if the travel demand is taken into account. Likewise, combining a person-based approach with regional concerns would entail a significant data gathering and an appropriate modeling. It would also guarantee a full multiscale analysis.

\footnotetext{
${ }^{22}$ The authors write: "[...] to live in Songjiang, but to work in the central city," has not been achieved. The Inner Ring station areas do not appear to perform much better in this regard; even though the TOD concept was applied to these areas, actual impact of the rail transit has been quite modest" (Pan, Shen, \& Liu, 2011).

23 "The more general lesson that is learned about this evidence can be developed at two levels. First, the idea that rail is able to contribute to improve accessibility in an already well transit-served urban area. Then, the need, to achieve this statement, to carry out a schedule modeling approach of transit service, because it's the only one which can reveal good or bad coordination regarding transit timetables" (L'Hostis et al., 2009, p. 46, personal translation).
} 
In fact, as the complexity of the urban planning projects is not declining, the assessment methods would continue to deal with multiscale and complex processes.

\section{$7 \quad$ Acknowledgments}

Special thanks go to the editor and the reviewers for providing meaningful recommendations for improving this contribution. 


\section{References}

Balz, V., \& Schrijnen, J. (2011). From concepts to projects: Stedenbaan, the Netherlands. In C. Curtis, J. L. Renne \& L. Bertolini (Eds.), Transit oriented development. Making it happen. Farnham and Burlington, UK: Ashgate.

Baptiste, H., \& L'Hostis, A. (2002). Évaluation multimodale des systèmes de transport en Nord-Pas de Calais et en Languedoc-Roussillon. Enjeux pour l'aménagement de territoires régionaux. Approche par analyse de la qualité des services des transports en commun et de l'accessibilité routière. (Research Report CESA-INRETS). Villeneuve d'Ascq, France: Centre d'Études Supérieures en Aménagement/Institut National de Recherche sur les Transports et leur Sécurité.

Benenson, I., Ben Elia, E., Rofé, Y., \& Rosental, A. (2016). Estimation of urban transport accessibility at the spatial resolution of an individual traveler. In V. Thakuriah, N. Tilahun, \& M. Zellner (Eds.), Seeing Cities Through Big Data (pp. 383-404). New York: Springer Geography.

Benenson, I., Martens, K., Rofé, Y., \& Kwartler, A. (2010). Public transport versus private car GISbased estimation of accessibility applied to the Tel Aviv metropolitan area. Annals of Regional Science, 47, 499-515.

Bertolini, L., Le Clercq, F., \& Kapoen, L. (2005). Sustainable accessibility: A conceptual framework to integrate transport and land use plan-making. Two test-applications in the Netherlands and a reflection on the way forward. Transport Policy, 12, 207-220.

Bristow, G., Farrington, J., Shaw, J., \& Richardson, T. (2009). Developing an evaluation framework for crosscutting policy goals: The Accessibility Policy Assessment Tool. Environmental Planning A, 41(1), 48-62.

Calthorpe, P. (1993). The next American metropolis—ecology, community, and the American dream. Princeton, NJ: Princeton Architectural Press.

Cervero, R. (1989). America's suburban centers: The land use-transportation link. Boston, MA: UnwinHyman.

Cervero, R. (2013). Linking urban transport and land use in developing countries. Journal of Transport and Land Use, 6(1), 7-24.

Cervero, R., \& Kockelman, K. (1997). Travel demand and the 3Ds: Density, diversity, and design. Transportation Research Part D: Transport and Environment, 2(3), 199-219.

Chenu, A. (2002). Les horaires et l'organisation du temps de travail. Economie et Statistique, 352-353, $151-167$.

Conesa, A. (2010). Modélisation des réseaux de transport collectifs métropolitains vers la structuration territoriale des réseaux. Applications au Nord-Pas-de-Calais et à Provence-Alpes-Côte d'Azur (PhD thesis). Villeneuve-d'Ascq, France: Université de Lille.

Conesa, A. (2012). Accessibilités et discontinuités spatiotemporelles en Nord Pas-de-Calais. Une région carrefour au territoire fragmenté? Territoires En Mouvement, 16(Special Issue: Région, régionalisation, régionalisme), 18-36.

Conesa, A. \& Leysens, T. (2015, August) Space and... time! Relevance and limits of schedule databases in accessibility analysis. Paper presented at the ERSA 55th Congress World Renaissance: Changing roles for people and places, Special Session on New Data and Methods in Accessibility Analysis, Lisbon, Portugal.

Conesa, A., \& L'Hostis, A. (2011). Defining intermodal accessibility. In A. Banos \& T. Thévenin (Eds.), Geographical information and urban transport systems (pp. 53-82). London: Wiley-ISTE Ltd.

Curtis, C., Renne, C. L., \& Bertolini, L. (Eds.). (2009). Transit oriented development. Making it happen. Farnham and Burlington, UK: Ashgate. 
Daganzo, C. F. (1998). Reversibility of the time-dependent shortest path problem. (Research Report ITS Berkeley). Berkeley, CA: Institute of Transportation Studies, University of California.

Dittmar, H., \& Poticha, S. (2004). Defining transit-oriented development: The new regional building block. In H. Dittmar \& G. Ohland (Eds.), The new transit town: Best practices in transit-oriented development (pp. 19-40). Washington, DC: Island Press.

Fosset, P., Marilleau, N., Banos, A., Beck, E., Chardonnel, S., Lang, C., Piombini, A., Leysens, T., Conesa, A., André-Poyaud, I., \& Thévenin, T. (2016). Exploring intra-urban accessibility and impacts of pollution policies with an agent-based simulation Platform: GaMiroD. Systems, 4(1), 5.

Geurs, K. T., \& Ritsema van Eck, J. (2001). Accessibility measures: Review and applications. (Research Report RIVM). Bilthoven, Netherlands: Rijksinstituut voor Volksgezondheid en Milieu.

Geurs, K. T., \& van Wee, B. (2004). Accessibility evaluation of land-use and transport strategies: Review and research directions. Journal of Transport Geography, 12(2), 127-140.

Hägerstrand, T. (1970) What about people in regional science? Papers of the Regional Science Association, 24, 7-21.

Hägerstrand, T. (1985). Time-geography: Focus on the corporeality of man, society, and environment. In S. Aida (Ed), The science and praxis of complexity: Contributions to the symposium held at Montpellier, France (pp. 193-216). Tokyo: United Nations University Press.

Handy, S. (1994). Highway blues, nothing a little accessibility can't cure. Access, 5, 2-8.

Kalsas, B. T., \& Aase, E. (1997). Modelling accessibility for public transport in an urban context. Paper presented at the 37th European Congress of Regional Science Association, Rome, Italy.

Kim, H. M., \& Kwan, M. P. (2003). Space-time accessibility measures: A geocomputational algorithm with focus on opportunity set and possible activity duration. Journal of Geographical Systems 5, $71-$ 91.

Knowles, R. D. (2012). Transit oriented development in Copenhagen, Denmark: From the Finger Plan to Ørestad. Journal of Transport Geography, 22, 251-261. doi: http://dx.doi.org/10.1016/j. rser.2013.03.062

Kwan, M. P. (1997). GISICAS: An activity-based travel decision support system using a GIS-interfaced computational-process model. In D. F. Ettema \& H. J. P. Timmermans (Eds.), Activity-based approaches to travel analysis (pp. 263-282). New York: Pergamon.

Kwan, M. P. (1998). Space-time and integral measures of individual accessibility: A comparative analysis using a point-base framework. Geographical Analysis, 3(30), 191-216.

Leinberger, C. (2009). The option of urbanism: Investing a new American dream. Washington, DC: Island Press.

Lenntorp, B. (1978). A time-geographic simulation model of individual activity programs. Human activity and time-geography. In T. Carlstein, D. Parkes \& V. Thrift (Eds.), Timing space and spacing time (pp. 62-180). London, UK: Edward Arnold.

Leslie, E., Butterworth, I., \& Edwards, M. (2006, October). Measuring the walkability of local communities using Geographic Information Systems data. Paper presented at Walk-21, The Next Steps, 7th International Conference on Walking and Liveable Communities, Melbourne, Australia.

L'Hostis, A. et al. (2009). Concevoir la ville à partir des gares. (Final Report of Bahn.Ville 2 Project). Paris: IFSTTAR, Université Paris Est Marne-la-Vallée.

Liao, F., Arentze, T., Molin, E., Bothe, W., \& Timmermans, H. (2015). Effects of land-use transport scenarios on travel patterns: A multi-state super network application. Transportation, 44(1), 1-25.

Litman, T. (2010). Affordable-accessible housing in a dynamic city. Why and how to increase affordable housing development in accessible locations. (Research Report VTPI). Victoria, BC: Victoria Transport Policy Institute. 
Lo Feudo, F. (2014). A TOD scenario for the Nord-Pas-de-Calais region, teaching of an integrated transportation-land use modeling. Paper presented in Mobil. TUM 2014, International Scientific Conference on Mobility and Transport, Sustainable Mobility in Metropolitan Regions, Munich, Germany.

Marshall, W. E., \& Garrick, N. W. (2010). The effect of street network design on walking and biking. Transportation Research Record, 2198, 103-115.

McNally, M. G., \& Rindt, G. R. (2007). The activity-based approach. In D. Hensher \& K. J. Button (Eds), Handbook of Transport Modeling (pp. 53-68). Oxford, UK: Pergamon Press [2nd Edition].

Menerault, P., Barré, A., Conesa, A., L'Hostis, A., Pucci, P., \& Stransky, V. (2006). Multipolarités urbaines et nouvelles organisations intermodales. (Research Report GRRT). Villeneuve-d'Ascq, France: Groupement Régional de Recherche sur les Transports.

Naess, P. (2011). New urbanism or metropolitan-level centralization? A comparison of the influences of metropolitan-level and neighborhood-level urban form characteristics on travel behavior. Journal of Transport and Land Use, 4(1), 25-44.

Neutens, T., Delafontaine, M., Scott, D. M., \& Demaeyer, P. (2012). An analysis of day-to-day variations in individual space-time accessibility. Journal of Transport Geography, 23, 81-91.

Neutens, T., Witlox, F., \& Demaeyer, P. (2007). Individual accessibility and travel possibilities: A literature review on Time-Geography. European Journal of Transport and Infrastructure Research, 7(4), $335-352$.

Newman, P., \& Jennings, I. (2008). Cities as sustainable ecosystems: Principles and practices. Washington, DC: Island Press.

Newman, P., \& Kenworthy, J. (1989). Cities and automobile dependence: A sourcebook. Aldershot, UK: Ashgate Publishing.

Ohmori, N., Muromachi, Y., Harata, N., \& Ohat, K. (1997). A study on accessibility and going-out behavior of aged people considering daily activity pattern. Journal of the Eastern Asia Society for Transportation Studies, 3, 139-153.

Pan, H., Shen, Q, \& Liu, C. (2011). Transit oriented development at urban periphery. Insights from a Shanghai Case Study. Transportation Research Record, 2245, 95-102.

Papa, E., Moccia, F. D., Angiello, G., \& Inglese, P. (2013). An accessibility planning tool for network transit ooriented development: SNAP. Planum, the Journal of Urbanism, 2(27), 1-9.

Rietveld, P., \& Bruinsma, F. (1998). Is transport infrastructure effective? Transport infrastructure and accessibility: Impacts on the space economy. Berlin, Germany: Springer.

Rousseau C., Gautier, M., \& Chapouthier, A. (2013). Horaires atypiques de travail, le point des connaissances. (Technical Report INRS). Paris: Institut National de Recherche et de Sécurité.

Salonen, M., \& Toivonen, T. (2013). Modelling travel time in urban networks: Comparable measures for private cars and public transports. Journal of Transport Geography, 31, 143-153.

Schneider, J. (2012). Describing and illustrating the extended transit-oriented development (E-TOD) concept. Retrieved from http://faculty.washington.edu/jbs/itrans/e-tod.htm.

Scott, D. M., \& Horner, M. W. (2008). The role of urban form in shaping access to opportunities. An exploratory spatial data analysis. Journal of Transport and Land Use, 1(2), 89-119.

Shiftan, Y. (2008). The use of activity-based modeling to analyze the effects of land-use policies on travel behavior. Annals of Regional Sciences, 1(41), 79-97.

SRADDT. (2013). Regional Planning Scheme (Schéma Régional d'Aménagement et de Développement Durable du Territoire). Région Nord - Pas-de-Calais.

TRB. (2007). Transit oriented development: Traveler response to transportation system changes. (Research report). Washington, DC: Transportation Research Board.

van Wee, B., Bohte, W., Molin, E., Arentze, T., \& Liao, F. (2014). Policies for synchronization in the 
transport-land-use system, Transport Policy, 31, 1-9.

Vilhelmson, B. (1999). Daily mobility and the use of time for different activities. The case of Sweden. GeoJournal, 48, 177-185. doi: 10.1023/A:1007075524340

Weber, J., \& Kwan, M. P. (2003). Evaluating the effects of geographic context on individual accessibility: A multilevel approach. Urban Geography, 8(24), 647-671.

Wu, Y. H., \& Miller, H. (2001). Computational tools for measuring space-time accessibility within transportation networks with dynamic flow. Journal of Transportation and Statistics, 4(2/3), 1-14.

Wu, F., Shen, J., \& Zu, Y. (2011, September). From mobility to accessibility: The key to sustainable development of TOD. Paper presented on the 2011 International Conference on Electrical and Control Engineering (ICECE), Yichang, China. 


\section{Appendix}

Table A1: Model parameters

\begin{tabular}{|c|c|}
\hline Parameter & Typical value \\
\hline Walking speed & $3 \mathrm{~km} / \mathrm{h}$ \\
\hline Minimum transfer time requirement \\
\hline Train - Train & 3 minutes \\
\hline Urban - Train & 5 minutes \\
\hline Urban - Urban & 3 minutes \\
\hline
\end{tabular}

Table A2: The 14 major cities and their corresponding nodes in the graph

\begin{tabular}{|l|c|}
\hline City & Nearest transit station to city center \\
\hline Lille & Train stations (Lille-Flandres + Lille-Europe) \\
\hline Cambrai & Train station \\
\hline Maubeuge & Train station \\
\hline Douai & Palais de justice (Urban bus station) \\
\hline Béthune & Hôtel des postes (Urban bus station) \\
\hline Arras & Robespierre (Urban bus station) \\
\hline Dunkirk & Train station \\
\hline Lens & Saint-Léger (Local coach station) \\
\hline Valenciennes & Hôtel de Ville (Tramway station) \\
\hline Calais & Train station \\
\hline Boulogne & Train station \\
\hline Tourcoing & Tourcoing centre (VAL station) \\
\hline Armentières & Hôtel de Ville (Urban bus station) \\
\hline Ascq & Train station \\
\hline
\end{tabular}

